\title{
The Consequences of Fiscal Stimulus on Public Debt: A Historical Perspective
}

\author{
W. D. McCausland and I. Theodossiou \\ Department of Economics and Centre for European Labour Market Research \\ University of Aberdeen
}

June 22, 2015

\begin{abstract}
The current policy agenda of neoclassical macroeconomics, as expressed within conservative political circles in the United Kingdom and European Union, is that fiscal contraction is the lever that can bring about recovery from the current economic downturn. Allegedly, the reason is that when business sees that the government balance sheet is improving - and public debt declining - there will be greater confidence in the country's economic prospects and this increased confidence will lead to higher investment. This in turn will lead to growth and the road to economic recovery. This study examines the impact of government stance on public debt for eleven OECD countries for which data on the relevant factors are available from 1881 to 2011. Contrary to traditional predictions, it turns out that over this long historical span, fiscal contractions deteriorated rather than improved public debt as a percentage of GDP. This implies that fiscal austerity exacerbates the lack of demand and deteriorates rather than enhances the prospects of economic recovery.
\end{abstract}

Keywords: debt, deficit, inequality

JEL: E62, E24, N10

Acknowledgements: The comments of two anonymous referees of this journal are gratefully acknowledged. The authors are also grateful to the participants of the History of Economic Thought sessions of the Scottish Economic Conference 2015 and of the 17th Annual Conference of Greek Historians of Economic Thought, 2015. 


\section{Introduction}

Deficit reduction is not an end in itself. Its importance lies in improving productivity, real wages and living standards. If fiscal contraction actually reduces a nation's output, diminishes demand and raises unemployment, then deficit reduction is not capable of advancing the aim of increasing economic prosperity. Recent policies of pursuing harsh austerity, often under duress and despite high unemployment, have frequently led to countries being unable to service their debts, forcing further cuts in public spending and tax increases to be introduced, while public debt as a percentage of output continues to worsen. Ordinarily, this outcome is not entirely surprising. Recessions are caused by demand deficiency - a level of demand below that which an economy is potentially able to produce. Fiscal contraction causes a reduction in spending that further lowers demand. In turn, this causes a further reduction in the production of goods and services as businesses cut production to the level of effective demand and hence further reduction in the nation's gross domestic product (GDP). Nevertheless, the proponents of austerity argue that, just as households sooner or later have to live within their means, thus national governments should likewise curtail spending to match tax revenues. They argue that austerity policies promote confidence within business that the government is determined to, and has the capability to, live within its means. It is suggested that increased confidence increases investment spending which in turn more than compensates for the contractionary effects of the initial decrease in government spending. This line of argument recently came to prominence in work by Alesina and Ardagna (1998, 2010), who claimed that they uncovered strong evidence of contractionary fiscal policy having positive confidence effects on economic expansion and strong historical evidence of expansionary fiscal austerity.

In contrast, Callegari et al. (2012) show that fiscal contraction and, in particular, cuts to public expenditure, can prolong recessions without generating the expected fiscal saving. They also argue that reductions in public spending have strong effects on consumption. Fiscal austerity during a recession seems to aggravate the costs of fiscal adjustment and the slow the reduction in the debt-to-GDP ratio. This in turn can aggravate weak market sentiment at times of low confidence, undermining the fiscal austerity efforts altogether.

This argument is supported by Chick and Pettifor (2011), who contrast the fiscal consolidations of pre-war Britain during which the public debt ratio increased and macroeconomic conditions worsened, with the post-war fiscal expansion during which the debt ratio falls and the economy prospered. In periods of recession, increases in public investment generate a multiplier effect, boosting incomes as well as tax revenue, increasing private sector activity, and reducing debt servicing costs and benefit payments. To paraphrase Keynes, "expenditure creates its own income".

Pasinetti (1989) and Dalziel (1991) examine the relationship between the distribution of income and the method of government finance following Kaldor (1956), and confirm that both Kaldor's theory of income distribution and the Cambridge theory of the rate of profits are robust to a range of methods of financing budget deficits. However, Pollin (2012) gives some alternative arguments to the normal Ricardian equivalence hypothesis why expansionary fiscal policy in the US during the 2008 financial crisis might not have the results expected - reliance on tax cuts, reduction in household wealth holding back consumption, and credit markets being locked up. Moreover, Stockhammer (2013) argues inequality has been the root cause of the recent economic crisis, driving down aggregate demand, partly due to the poor having relatively high marginal propensities to consume, and partly due to a falling wage share. Crotty (2012) argues that conservative macroeconomics, together with a focus on austerity, generates slow growth, rising inequality and rising deficits, and in turn, demands for further austerity. Taylor et al. (2012) gives a parallel exposition of the theoretical underpinnings of this paper - showing a policy induced 
expansion in the deficit would increase growth and reduce the debt-output ratio in the long run.

Finally, Blanchard and Leigh (2013) emphasise that there is no consistent evidence justifying the use of contractionary fiscal policy to secure economic growth. Fiscal adjustment in response to elevated levels of government debt and future pressures on public finances is only one of many possible factors that need to be considered in determining the appropriate pace of fiscal consolidation for any country.

This brief literature review shows that there is not only a paucity of consistency of the effects of fiscal austerity on economic growth and prosperity but also ambiguous effects on the debt-to-GDP ratios across counties. This paper aims to further investigate the effects of fiscal contraction on national debt and economic activity. It attempts to disentangle the transitory and permanent effects of fiscal austerity on debt-to-GDP ratio using a panel of eleven OECD countries for which data on the relevant factors are available from 1881 to 2011 . Contrary to traditional predictions, it turns out that over this long historical span, fiscal contractions deteriorated rather than improved public debt as a percentage of GDP. This implies that fiscal austerity exacerbates the lack of demand and deteriorates rather than enhances the prospects of economic recovery. Furthermore, the paper examines the hidden cost of fiscal austerity - the waste of valuable human resources - by examining the relationship between the primary deficit ratio and the change in the unemployment rate. The results indicate a robust inverse relationship suggesting that cuts to government expenditure increases unemployment.

The paper is structured as follows. Section 2 briefly sets up the theoretical relationships to be confronted with the historical record. Section 3 describes the data that has been employed in this study. In Section 4 the methodology to be used in the empirical analysis is outlined. Section 5 contains a discussion of the empirical results. In section 6 extensions to the analysis to capture the welfare loss from austerity are examined. Section 7 concludes.

\section{Theoretical Considerations}

The theoretical starting point is the standard debt accumulation identity describing debt accumulation being attributable to the sum of the the effect of the addition to the stock of debt resulting from an excess of government spending over tax revenues (the primary deficit) plus the debt servicing obligation on the existing stock of debt.

$$
\Delta D \equiv(G-T)+i D
$$

where $D$ is real debt, $(G-T)$ is the real primary deficit, and $i$ is the real interest rate on public debt. By dividing through by real GDP, $Y$ and defining $d \equiv D / Y, g \equiv G / Y, t \equiv T / Y$ and $y \equiv \Delta Y / Y$ equation (1) can be written as

$$
\Delta d=(g-t)+(i-y) d
$$

where $d$ is the real debt ratio (the ratio of debt to GDP), $(g-t)$ is the ratio of real primary deficit to GDP, and $y$ is the GDP growth rate ${ }^{1}$. An estimatable form of equation (2) would be

$$
\Delta d=b_{0}+b_{1} f+b_{2} i-b_{3} y
$$

where $f \equiv(g-t)$ is the real primary deficit ratio. The debt servicing components $b_{2} i-b_{3} y$ may be considered to capture the long run effect of debt accumulation and economic growth. Equations 1 and 2 are in line with similar formulations for the evolution of government debt in studies by Hall and Sargent (2011), Mason and Jayadev (2014) and

\footnotetext{
${ }^{1}$ Since $d \equiv D / Y, D=d Y$, and hence $\Delta D=Y \Delta d+d \Delta Y$ and thus $\Delta D / Y=\Delta d+d \Delta Y / Y=\Delta d+d y$.
} 
DeGrauwe and Ji (2013). This literature is mainly concerned to show how GDP growth, inflation and interest rates affect the evolution of the debt ratio and the household debt ratio (Hall and Sargent, 2011; Aizenman and Marion, 2009; Buiter, 1985; Das, 2011; Rangarajan and Srivastava, 2003; Giannitsarou and Scott, 2008; Abbas et al., 2011) in contrast to this study which focuses on the effects of government stance on the public debt.

\section{Data}

The data in this paper comprises a panel of 11 OECD countries: Belgium, Canada, Denmark, France, Germany, Italy, the Netherlands, Norway, Sweden, the UK and the US. Data is annual and spans the period 1881-2011. Data on the real GDP growth rate, real debt ratio, real primary deficit ratio and real interest rate on public debt are from Mauro et al. (2013), and data on the unemployment rate is a constructed time series derived from published OECD data combined with data obtained from the US Department of Labor: Bureau of Labor Statistics, and Galenson and Zellner (1957). A common problem with long data series is that some data points are missing, particularly during the first and second world wars. In such cases data points are generated by linear interpolation (Intriligator, 1978), and for the period of the first and second world wars, two dummy variables are introduced.

\section{Methodology}

In terms of the econometric approach a standard fixed effects regression model is estimated that has the form

$$
d_{j t}=\alpha_{t}+X_{j t} \beta+E_{j t} \gamma+S_{j}+\epsilon_{j t}
$$

where for country $j$ and year $t, d$ is the change in the real debt ratio, $X$ is a vector of other controls, $E$ is a measure of real primary deficit ratio, $S$ is a fixed effect control for the time-invariant state-specific impacts on the real primary deficit ratio, and $\epsilon$ is an error term.

Unfortunately, a-priori there is no theory to guide researchers as to the length or the shape of the lag structure that is appropriate to capture any lagged effects of the deficit ratio on the debt ratio, and therefore, there is no a consensus on how to model these dynamic effects. One way to circumvent this issue of lags is to make a distinction between the permanent and transitory components of the real primary deficit on national debt. This concept is similar to the formulation for income and consumption by Friedman (1957) and employs the standard permanent-transitory decomposition using the Mundlak (1978) methodology. This methodology uses a random effects estimator. However, in Mundlak's specification the potential correlation between unobservable characteristics and, here, the real primary deficit ratio, is accounted for and it is often interpreted as a bridge between the two estimators (Greene, 2008)(pp. 209-10). Thus, the advantage of using the Mundlak methodology is its ability to identify the 'permanent' and 'temporary' effects of the real primary deficit on national debt, in contrast to earlier literature (Hall and Sargent, 2011; Mason and Jayadev, 2014; Aizenman and Marion, 2009; Buiter, 1985; Das, 2011; Rangarajan and Srivastava, 2003; Giannitsarou and Scott, 2008; Abbas et al., 2011; DeGrauwe and $\mathrm{Ji}, 2013$ ) which is mainly concerned of how GDP growth, inflation and interest rates determine the evolution of the debt ratio.

Thus, following Mundlak (1978) the effect, $S_{j}$, is assumed to be a random effect disturbance term and the real primary deficit ratio and other important variables are allowed to have both a 
transitory and permanent (fixed) effect. Hence, instead of estimating equation (4), the following specification is estimated:

$$
\begin{gathered}
H_{j t}=\alpha_{t}+X_{j t} \beta+E_{j t} \gamma+I_{j t} \delta+\bar{E}_{j} \tilde{\gamma}+\bar{I}_{j} \tilde{\delta}+\epsilon_{j t}+\left(S_{j}-E\left(S_{j} \mid X_{j}, E_{j}, I_{j}\right)\right) \\
H_{j t}=\alpha_{t}+X_{j t} \beta+E_{j t} \gamma+I_{j t} \delta+\bar{E}_{j} \tilde{\gamma}+\bar{I}_{j} \tilde{\delta}+\epsilon_{j t}+u_{t}
\end{gathered}
$$

where $I$ are other important variables, and $\bar{E}$ and $\bar{I}$ are the mean levels of real primary deficit and other important variables, respectively, for each state $j$ and $E\left(s_{j} \mid X_{j}, E_{j}, I_{j}\right)=\bar{E}_{j} \tilde{\gamma}+\bar{I}_{j} \tilde{\delta}$. Greene (2008) argues that the above formulation retains the random effects specification but should also appropriately deal with the problem of any correlation between the unobserved effects $\left(S_{j}\right)$ and the regressors. The above procedure introduces dynamics on the effects of the real primary deficit ratio and other important variables on national debt. To fully identify the transitory and permanent effects, the variable transformation suggested by Ferrer-i Carbonell and van Praag (2002) is used which, in this context, redefines the term $E_{j t} \gamma+\bar{E}_{j} \tilde{\gamma}$ in equation (6) to $\left(E_{j t}-\bar{E}_{j}\right) \gamma+\bar{E}_{j}(\gamma+\tilde{\gamma})$ and redefine $I_{j t} \delta+\bar{I}_{j} \tilde{\delta}$ to $\left(I_{j t}-\bar{I}_{j}\right) \delta+\bar{I}_{j}(\delta+\tilde{\delta})$. This allows an explicit decomposition of the impact of real primary deficit and other important variables on national debt into two distinct effects. Differences across countries in the average real primary deficit and other important variables measure the permanent effects and the deviations from the average real primary deficit, $\left(E_{j t}-\bar{E}_{j}\right)$, and other important variables $\left(I_{j t}-\bar{I}_{j}\right)$, per state, measure the transitory effects. The coefficients, $\gamma$ and $\delta$, reflect transitory effects and the coefficients $(\gamma+\tilde{\gamma})$ and $(\delta+\tilde{\delta})$ measure permanent effects. Note that since the 'transitory' effects are parameterised as differences in the real primary deficit ratio, the relative importance of the real primary deficit ratio on national debt in both a short-term and a long-term effect can be assessed. If these effects point in different directions, then their relative importance can be evaluated.

In addition, Egger and Pfaffermayr (2002) demonstrate using Monte Carlo simulations that the Mundlak model can be viewed as an approximation of a general dynamic autoregressive distributed lag model. They also show that the Mundlak model is a perfect representation of a model with lagged exogenous variables and the unspecified lag dynamics is fully compensated by the inclusion of the group mean as a control. In addition, they demonstrate that the Mundlak model provides an approximation of the temporary and permanent effects, when inference in a dynamic model is not feasible. This interpretation is widely used in the literature. For instance van Praag et al. (2003) and Gottschalk et al. (1994) apply this concept in a micro panel context and Afonso et al. (2011) in a macro panel context and use a similar interpretation of the Mundlak decomposition.

It is worth emphasising that the Mundlak methodology offers an economically interpretable fixed effect, since changes in this 'fixed effect' correspond to changes in average real primary deficit. For standard fixed effects, in general one cannot give an economic interpretation of the fixed effect. Although the Mundlak specification provides a convenient avenue for identifying the permanent and transitory effects of the variables of interest, a potential problem may be that these variables may be correlated with the state-level random effect, $u_{j}$. This may cause the estimates in Table 1 to be biased due to endogeneity in the relationship. To address this issue, this paper employs the Hausman and Taylor (1981) (HT) correction. The HT procedure can be used to deal with the problem of endogeneity and test whether the results in Table 1 are robust to endogeneity correction. The HT procedure is an instrumental variables estimator that controls for any correlation between the independent variables and the random effect. Starting with equation (5) above, both the transitory and permanent real primary deficit ratio are assumed to be correlated with the state random effect. The other time varying and time invariant variables are assumed exogenous. A within- or fixed-effects estimator of that equation removes the time 
invariant covariates. Using the estimates from that regression, the within-residuals are then calculated. These residuals are then used as the dependent variable in a regression including the time invariant regressors using the time varying variables as instruments. This procedure produces consistent estimates of all of the coefficients in equation (5).

\section{$5 \quad$ Results}

The discussion of results is divided into two subsections. First, the main results are discussed detailing the impact of the primary deficit ratio on the change in the debt ratio. In the second subsection the transitory-permanent dichotomy of the deficit ratio - debt relationship is considered.

\subsection{The effect of change on real primary deficit on the change in debt: basic results}

One issue of concern is the possibility that the Mundlak random effects estimation does not produce results in line with the fixed effects estimation. To investigate this, the results of the fixed and random effects estimation are similar and compatible for the same period. In this subsection the results of the fixed and random effects estimation are compared. Table 1 column 1 reports the results of the fixed effects estimation of equation (4) including in $X$ only two dummy variables for the effects of World War I and II. The results show a negative and statistically significant relationship between the primary government deficit ratio $(f)$ and the change in the debt ratio $\Delta d$. Thus, from column 1 of Table 1 it can be seen that a rise in the real primary deficit ratio $f$ by $1 \%$ reduces the change in the debt ratio by $0.76 \%$. Interestingly, the results of the fixed effects estimation are very similar to the random effects estimation. This suggests that the effects of the primary government deficit ratio on the change in the debt ratio are robust to the estimation methodology.

In table 1, column 2 the random effects regressions reveal a consistent negative relationship in the neighborhood of previous estimates. Hence, increases in government expenditure reduce the national debt. A rise in the real primary deficit ratio $f$ by $1 \%$ reduces the change in the debt ratio by $0.73 \%$.

These results show a consistency and robustness between the fixed and random effects estimations. The results are contrary to prior expectations arising from a cursory appeal to the standard stock-flow notion which states that the stock of debt is augmented by the flows of excesses of government spending over tax revenues. However, historical data reveals long periods where primary deficits are increasing but debt ratios are falling. This paper confirms this inverse relationship identified by Chick and Pettifor (2011) who contrast the fiscal consolidations of pre-war Britain during which the public debt ratio increased and macroeconomic conditions worsened, with the post-war fiscal expansion during which the debt ratio falls and the economy prospered. In periods of recession, increases in public investment generate a multiplier effect, boosting incomes as well as tax revenue, increasing private sector activity, and reducing debt servicing costs and benefit payments.

A further pair of estimations augments the above estimations by including in $X$ other important determinants of the national debt as indicated by equation (4): the real GDP growth rate, real interest rate on government debt and the real primary debt ratio. The latter variable controls for the state of national finances of the country. Table 1, columns 3 and 4 shows the fixed and random effects respectively. It can be seen that a $1 \%$ rise in the real primary deficit ratio $f$ reduces the change in the debt ratio by $0.96 \%$ in the fixed effects estimation and $0.93 \%$ in 
the random effects estimation. Overall, the results are qualitatively similar to the earlier results, and once again show a consistency and robustness between the fixed and random effects estimations. The first step is to examine whether the results confirm the expected long run results of an inverse relationship between national debt and economic growth and a positive relationship between national debt and the cost of debt repayment. Interestingly, the coefficient on $(i-y)$ in equation (2) would be, taking specification (4) as an example, $0.260-0.493<0$ implying a stable steady state with a positive debt (Pasinetti, 1989). One issue of concern is that the above results are derived for the long historical period 1881 to 2011 and do not make specific reference to the effects of the primary balance debt ratio during recessions. Nevertheless, a part of the policy discussion focuses on the effects of fiscal policy during recession ${ }^{2}$. The difficulty in addressing this issue is to identify specific common recessionary periods given the business cycles for the countries included in this study are not synchronised. However, two recessionary shocks, the Great Depression of the 1930s and the Great Recession post 2008-2009 are reasonably well synchronised. Thus, following DeGrauwe and $\mathrm{Ji}$ (2013), the above estimations are replicated for two periods: 1930-1932, and 2010-2011. Table 2 shows the results of this exercise. They confirm that there is a strong and significant negative effect of the real primary deficit ratio on the change in debt confirming that increases in government spending decrease the the national debt.

\subsection{The transitory-permanent dichotomy of the deficit ratio - debt relationship}

An issue of concern is the importance of lagged effects of the real primary deficit on national debt. If the impact of the real primary deficit is cumulative, then the effects of an increase in the real primary deficit on national debt may be observed for many years after the original increase. Hence, the effect of the real primary deficit ratio on national debt may take a long time to manifest itself, and one would not expect the only effect of real primary deficit on national debt to be of the contemporaneous nature modeled above.

The transitory-permanent dichotomy of the deficit ratio - debt relationship is considered, using equation (6). The results of this exercise are reported in columns 5 and 6 in Table 1. Specification (5) shows the simple Mundlak specification which decomposes the effects into a permanent and a transitory component for the key independent variable: the real primary deficit ratio. Specification (6) shows the full Mundlak specification which includes both the transitory and the permanent effects of all the independent variables. The consistent negative relationship between the real primary deficit ratio and the change in the debt ratio is maintained and is in the neighborhood of previous estimates. For example, from columns 5 and 6 of Table 1 it can be seen that a rise in the real primary deficit ratio $f$ by $1 \%$ reduces the change in the debt ratio by $0.95 \%$ (simple Mundlak specification) and, again, $0.95 \%$ (full Mundlak specification). It can be confirmed that there is little difference in the results between the important variables the two specifications. This shows that the relationship found in the 'within' estimator are also found in the 'between' estimators implied by the random effects regression. The results highlight that there are no statistically significant permanent effects. This evidence offers support for a Keynesian approach to policymaking during economic downturns.

Finally in this section the results of the Hausman and Taylor (HT) correction are presented to control for the possibility that the variables of interest may be correlated with the state-level random effect. The results of this exercise are reported in column 7 in Table 1 . The estimation results show that there is little difference between the real primary deficit and the other important

\footnotetext{
${ }^{2}$ We are grateful to an anonymous referee of the journal for this point.
} 
variables compared with previous specifications. For example, in specification (7), a rise in the real primary deficit ratio $f$ by $1 \%$ reduces the change in the debt ratio by $0.94 \%$. The coefficient on $(i-y)$ is $0.258-0.496<0$ again implying a stable steady state with a positive debt.

Overall, the empirical investigation above shows that the effects of government deficit spending is associated with reductions in the debt ratio. Austerity causes rather than alleviates the debt burden. The next section investigates how austerity not only does not improve economic performance but also imposes a major human cost on society. 


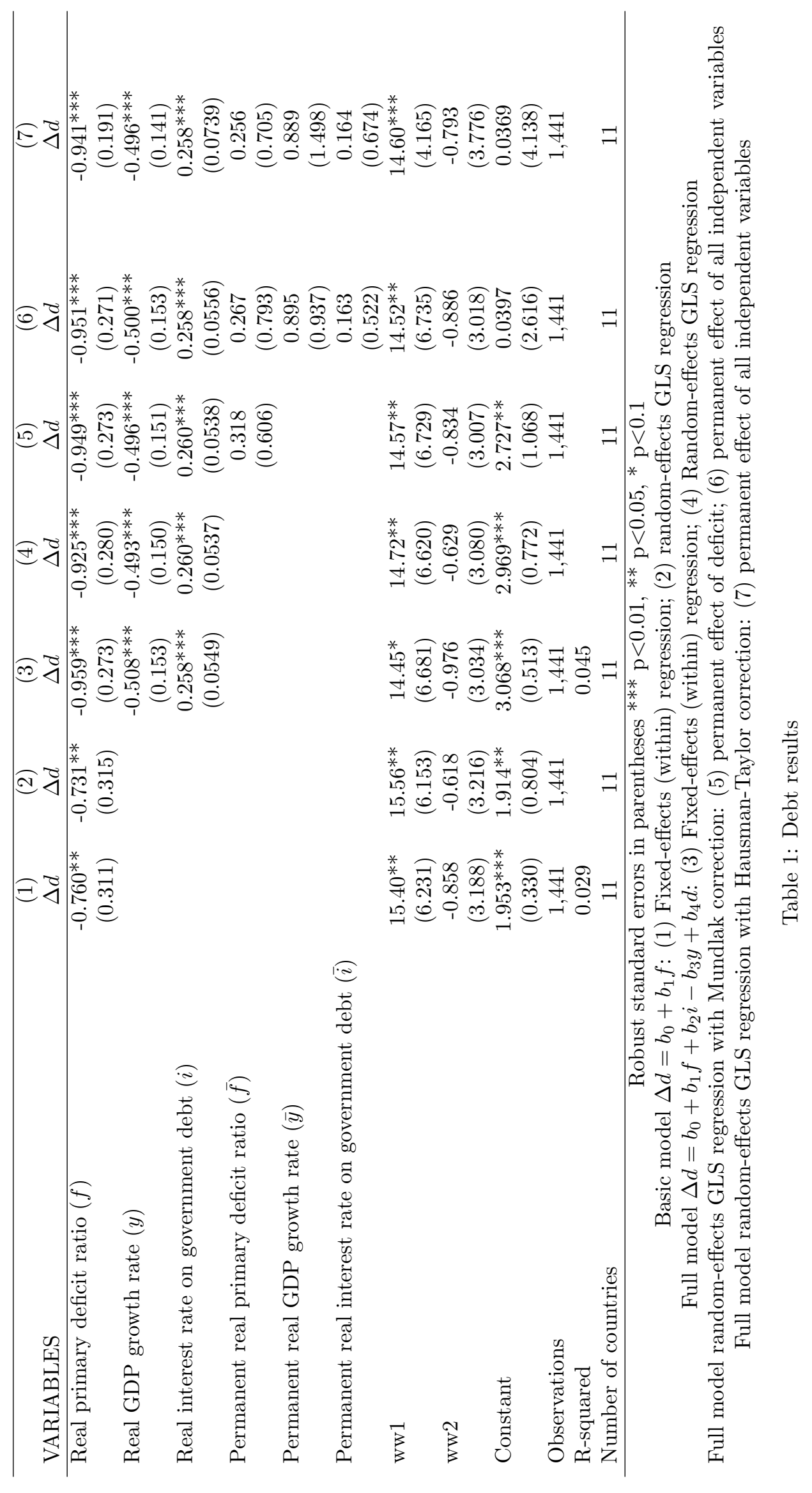




\begin{tabular}{|c|c|c|c|c|}
\hline VARIABLES & $\begin{array}{c}(1) \\
\Delta d(1930-32) \\
\end{array}$ & $\begin{array}{c}(2) \\
\Delta d(1930-32) \\
\end{array}$ & $\begin{array}{c}(3) \\
\Delta d(2010-11) \\
\end{array}$ & $\begin{array}{c}(4) \\
\Delta d(2010-11) \\
\end{array}$ \\
\hline Real primary deficit ratio $(f)$ & $\begin{array}{c}-0.811^{* * *} \\
(0.198)\end{array}$ & $\begin{array}{c}-0.835^{* * *} \\
(0.171)\end{array}$ & $\begin{array}{l}-1.915^{*} \\
(1.017)\end{array}$ & $\begin{array}{l}-1.091^{*} \\
(0.661)\end{array}$ \\
\hline Real interest rate on government debt $(i)$ & & $\begin{array}{c}1.920^{* * *} \\
(0.730)\end{array}$ & & $\begin{array}{c}0.375 \\
(0.476)\end{array}$ \\
\hline Real GDP growth rate $(y)$ & & $\begin{array}{l}-0.720 \\
(0.544)\end{array}$ & & $\begin{array}{c}-1.569^{* * *} \\
(0.360)\end{array}$ \\
\hline Constant & $\begin{array}{l}3.153^{* *} \\
(1.534)\end{array}$ & $\begin{array}{l}1.326 \\
(2.026)\end{array}$ & $\begin{array}{c}14.25^{* * *} \\
(3.411)\end{array}$ & $\begin{array}{l}4.055 \\
(5.331)\end{array}$ \\
\hline Observations & 30 & 30 & 45 & 33 \\
\hline Number of countries & 15 & 15 & 15 & 11 \\
\hline
\end{tabular}

Table 2: Supplementary results - periods of recession

\section{Extensions: the welfare loss of austerity}

A macroeconomic outcome of crucial importance in determining the prevalence of poverty is unemployment. As unemployment increases, more and more workers are not able to adequately provide for themselves and their families, and poverty increases. The overall unemployment rate gives an indication of the opportunity to work and hence should be expected to be an important determinant of poverty. Changes in the unemployment rate in turn may be affected by the fiscal stance of the government. In the previous two subsections, it has been established that cutting the real primary deficit ratio actually worsens the debt ratio. However, in addition to being ineffective in debt reduction, cutting the primary deficit also has the potential for incurring a human cost, most potently, unemployment. Stockhammer and Klär (2011) look at the relationship between unemployment and capital accumulation and the real interest rate ${ }^{3}$. They argue that unemployment policy should focus on stimulating capital accumulation rather than labour market reform. This view is supported by Chick and Pettifor (2011) who show that the post-war policy stance in the UK lasting through to the 1970s resulted in a steady reduction in unemployment and a period of steady growth and recovery of GDP. Moreover, they show that public debt as a proportion of GDP fell throughout this period. They conclude that fiscal policy focussed on employment and economic expansion was successful in delivering prosperity and employment. This section therefore investigates the impact of reductions in real primary deficit ratio on unemployment. The equation to be estimated is along the lines of the earlier specification as follows:

$$
\Delta u=b_{0}+b_{1} f+b_{2} i-b_{3} y+b_{4} d
$$

Due to data limitations, the data set is restricted to the period 1922-2010 and a subset of 9 OECD countries: Belgium, Canada, Denmark, France, Germany, the Netherlands, Sweden, the UK and the US.

\footnotetext{
${ }^{3}$ Stockhammer and Klär (2011) also motivates the inclusion of the interest rate and the growth rate of GDP in this paper.
} 
The results are presented in Table (3) in the same format as in the previous section. The parsimonious specifications (1) and (2) show the fixed and random effects estimations with the real primary deficit ratio $(f)$ as the sole explanatory variable, whereas specifications $(3)$ and (4) show the fixed and random effects estimations with the other key explanatory variables included. The estimates are consistent and robust, with a $1 \%$ rise in the primary deficit ratio $f$ being associated with around a $0.06 \%$ fall in the rate of change of the unemployment rate $\Delta u$.

Specification (5) shows the simple Mundlak correction which includes the permanent effect of the key independent variable: the real primary deficit ratio $\bar{f}$. Specification (6) shows the full Mundlak correction which includes the permanent effects of all the independent variables. The consistent negative relationship between the real primary deficit ratio and the change of the unemployment rate is maintained and is in the neighborhood of previous estimates. For example, in the full specification (6), a $1 \%$ rise in the primary deficit ratio $f$ is associated with a $0.06 \%$ fall in the rate of change of the unemployment rate $\Delta u$.

Finally, the results of the Hausman and Taylor (HT) correction are presented to control for the possibility that the variables of interest may be correlated with the state-level random effect. The results of this exercise are reported in column 7 in table 3 . The results show that there is little difference between the real primary deficit and the other important variables compared with previous specifications. For example, in specification (7), a a $1 \%$ rise in the primary deficit ratio $f$ is associated with a $0.06 \%$ fall in the rate of change of the unemployment rate $\Delta u$.

The results in table (3) thus show a robust inverse relationship between the real primary deficit ratio $(f)$ and the change in the unemployment rate $\Delta u$. All in all, increases in government expenditure reduce unemployment. Thus, policies of fiscal austerity in additional to having harmful effects on debt ratios, they also have additional social costs in increasing unemployment and wasting human and productive potential.

Column 7 of table 3 shows the results after controlling for endogeneity. Although the transitory effects remain strong and significant, the permanent effects turn out to be insignificant. These results imply that contractionary fiscal policy has an immediate an important effects on unemployment with the consequent detrimental effects of skills deterioration on human capital and wellbeing of the population. 


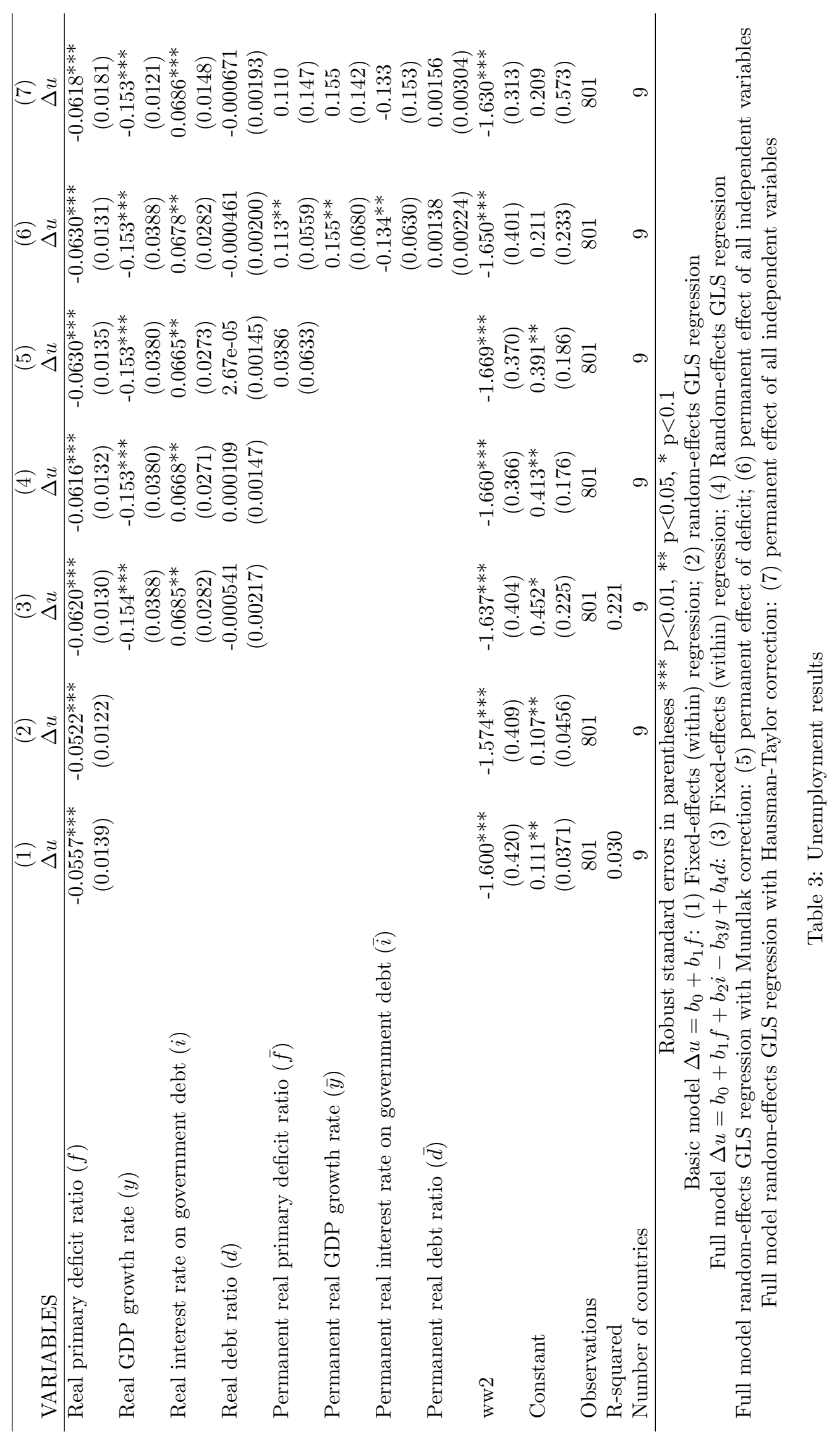




\section{Discussion and conclusions}

Historical data has identified long periods during which primary deficits are increasing but debt ratios are falling. This seems to be at odds with the standard stock-flow notion that the stock of debt is augmented by the flows of excesses of government spending over tax revenues. This paper has sought to investigate this puzzle and shed light on the effect of the primary government deficit on national debt.

Employing annual data that spans the period 1881-2011 for a panel of 11 OECD countries, an inverse relationship between the primary government deficit and national debt is found. Increases in government expenditure reduce the national debt. Conversely fiscal austerity turns out to increase the national debt. Furthermore cuts in government expenditure appear to not only to have transitory effects in increasing the national debt but also have significant permanent effects in worsening the public debt. Thus, fiscal austerity leads to worsening public debt. Furthermore a secondary effect of fiscal austerity is the important and negative impact on employment levels. The paper shows that fiscal austerity has at least significant transitory effects on increasing unemployment.

Taken together these results should cast some doubts on the merits of reducing public spending during periods of recession. Policies aimed at reducing the primary deficit would seem to actually worsen the debt ratio and increase unemployment.

The policy implications are profound, and controversial. The results imply that in periods of recession, far from pursuing an aggressive programme of austerity aimed at cutting the government deficit and involving substantial cuts to government spending, policy makers should be increasing public spending. If such spending is focussed on investment, rather than transfer payments (which are excluded from the measures of the government deficit used in this paper), then this can not only stimulate demand and employment in the short term, when it is sorely needed, but also expands capacity for the long term, mitigating problems of lack of supply capacity when the economy moves out of recession. These conclusions are at odds with the received wisdom of current political thinking, the media, and much of the academic literature, that promotes the notion of small government and appeal to a simple, but misleading, stock-flow idea that the stock of debt can be reduced by cuts to government spending. The findings of this paper supports the main thrust of Chick and Pettifor (2011) in face of the battery of attacks in the Economic Journal newsletter. Booth and Shackleton (2011) and Howells (2010) criticise the use of data averaged over multi-year periods, whereas Harrison (2011) proposes the use of the second difference of the debt ratio as the independent variable and varying the lag structure on the right hand side. This paper exploits annual data over a long span, and a employ robust theoretical specification to determine the estimatable equation. The results show a consistency and robustness between fixed and random effects estimations. The importance of lagged effects is acknowledged, using the Mundlak approach to explicitly consider the transitory-permanent dichotomy of the deficit ratio - debt relationship and Hausman and Taylor to account for the effects of endogeneity in the relationship. The results reveal that there is a positive and statistically significant transitory effect between the real debt ratio and the change in the debt ratio but no statistically significant permanent effects. Thus the results support the initial insights by Chick and Pettifor (2011) and, importantly, and lend substantial support for a Keynesian approach to policymaking during economic downturns.

\section{References}

Abbas, S. M. A., N. Belhocine, A. ElGanainy and M. Horton, "Historical Patterns of Public Debt: Evidence From a New Database," IMF Economic Review 59 (2011), 717742. 
Afonso, A., P. Gomes And P. Rother, "Short- and long-run determinants of sovereign debt credit ratings," International Journal of Financial Economics 16 (2011), 1-15.

Aizenman, J. And N. Marion, "Using inflation to erode the US public debt," Working paper 15562, NBER, 2009.

Alesina, A. And S. Ardagna, "Tales of fiscal adjustment," Economic Policy 13 (1998), 487545.

"Large Changes in Fiscal Policy: Taxes versus Spending," in Tax Policy and the Economyvolume 24 of NBER Chapters (National Bureau of Economic Research, Inc, 2010), 35-68.

Blanchard, O. J. And D. Leigh, "Growth Forecast Errors and Fiscal Multipliers," American Economic Review 103 (2013), 117-20.

Booth, P. And J. Shackleton, "Are we really suffering from "deficit fetishism"?," RES Newsletter 153 (2011), 17-22.

Buiter, W., "A guide to public sector debt and deficits," Economic Policy 1 (1985), 13-79.

Callegari, G., G. Melina And N. Batini, "Successful Austerity in the United States, Europe and Japan," IMF Working Papers 12/190, International Monetary Fund, July 2012.

Chick, V. And A. Pettifor, "The economic consequences of Mr Osborne. Fiscal consolidation: lessons from a century of UK macroeconomic statistics," Report, PRIME (Policy Research in Macroeconomics, London, May 31, 20112011.

Crotty, J., "The great austerity war: what caused the US deficit crisis and who should pay to fix it?," Cambridge Journal of Economics 36 (2012), 79-104.

DAlziel, P., "A generalisation and simplification of the Cambridge Theorem with budget deficits," Cambridge Journal of Economics 15 (1991), 287-300.

Das, P., "Decomposition of Debt-GDP Ratio for United Kingdom: 1984-2009," http://www.indiana.edu/ econdept/conference/jrc2011/das.pdf (2011).

DeGrauwe, P. And Y. Ji, "Panic-driven austerity in the Eurozone and its implications," http://www.voxeu.org/article/panic-driven-austerity-eurozone-and-its-implications (2013).

Egger, P. And M. Pfaffermayr, "Long run and short run effects in static panel models," in International Conference on Panel Datavolume B6-2 (10th International Conference on Panel Data, Berlin, July 5-6, 2002), 1-18.

Ferrer-i Carbonell, A. And B. M. van PraAg, "The subjective costs of health losses due to chronic diseases. An alternative model for monetary appraisal," Health Economics 11 (2002), 709-722.

Friedman, M. A., A Theory of the Consumption Function (Princeton University Press, 1957).

Galenson, W. And A. Zellner, "The measurement and behaviour of unemployment," International comparison of unemployment rates, NBER, 1957.

Giannitsarou, C. And A. Scott, "Inflation implications of rising government debt," Technical Report, NBER International Seminar on Macroeconomics 2006, 2008. 
Gottschalk, P., R. Moffitt, L. Katz and W. Dickens, "The Growth of Earnings Instability in the US Labor Market," Brookings Papers on Economic Activity 25 (1994), 217-272.

Greene, W. H., Econometric Analysis (Prentice Hall, 2008).

HALl, G. AND T. SARGENT, "Interest rate risk and other determinants of post-WWII US government debt/GDP dynamics," American Economic Journal: Macroeconomics 3 (2011), $192-214$.

Harrison, M., "Surely you're joking, Mr Keynes," RES Newsletter 155 (2011), 12-15.

Hausman, J. A. And W. E. Taylor, "Panel Data and Unobservable Individual Effects," Econometrica 49 (1981), 1377-1398.

Howells, P., "Support for deficit fetishism on the wane?," RES Newsletter 150 (2010), 18-20.

Intriligator, M. D., Econometric Models, Techniques and Applications (NJ: Prentice-Hall, 1978).

Kaldor, N., "Alternative theories of distribution," Review of Economic Studies 23 (1956), $83-100$.

Mason, J. AND A. JAYADEV, "Fisher dynamics in US household debt, 1929-2011," American Economic Journal: Macroeconomics 6 (2014), 214-234.

Mauro, P., R. Romeu, A. Binder And A. Zaman, "A Modern History of Fiscal Prudence and Profligacy," Working Paper 13/5, International Monetary Fund, Washington, DC, 2013.

Mundlak, Y., "On the Pooling of Time Series and Cross Section Data," Econometrica 46 (1978), 69-85.

Pasinetti, L. L., "Ricardian debt / taxation equivalence in the Kaldor theory of profits and income distribution," Cambridge Journal of Economics 13 (1989), 25-36.

Pollin, R., "US government deficits and debt amid the great recession: what the evidence shows," Cambridge Journal of Economics 36 (2012), 161-187.

Rangarajan, C. And D. Srivastava, "Dynamics of debt accumulation in India: impact of primary deficit, growth and interest rate," Economic and Political Weekly 38 (2003), 48514858.

Stockhammer, E., "Rising inequality as a cause of the present crisis," Cambridge Journal of Economics (2013).

Stockhammer, E. AND E. KLÄR, "Capital accumulation, labour market institutions and unemployment in the medium run," Cambridge Journal of Economics 35 (2011), 437-457.

Taylor, L., C. R. Proao, L. De Carvalho and N. Barbosa, "Fiscal deficits, economic growth and government debt in the USA," Cambridge Journal of Economics 36 (2012), 189204.

van Praag, B., P. Frijters and A. Ferrer-i Carbonell, "The anatomy of subjective well-being," Journal of Economic Behavior and Organization 51 (2003), 29-49. 